\title{
Analisis Perlakuan Akuntansi Aset Biologis pada Perum Perhutani KPH Jember
}

\author{
(The Analysis of Accounting Treatments of Biological Assets in \\ Perum Perhutani KPH Jember)
}

\author{
Wiyasih Zerlinda*, Indah Purnamawati, Yosefa Sayekti \\ Jurusan Akuntansi, Fakultas Ekonomi dan Bisnis, Universitas Jember (UNEJ) \\ Jln. Kalimantan 37, Jember 68121 \\ E-mail:wzerlinda@gmail.com
}

\begin{abstract}
Abstrak
Transformasi biologis terdiri atas proses pertumbuhan, perkembangan, degenerasi, produksi, dan prokreasi yang menyebabkan perubahan secara kualitatif dan kuantitatif dalam kehidupan hewan dan tumbuhan tersebut. Pengukuran pada aset biologis diperlukan bagi perusahaan agar pengukuran dilakukan secara wajar sesuai dengan kontribusi aset biologis dalam menghasilkan output dan keuntungan bagi perusahaan. PSAK 69 bertujuan untuk mengatur perlakuan akuntansi dan pengakuan yang berkaitan dengan agrikultur.Penelitian ini menggunakan pendekatan kualitatif, dimana penelitian ini dilakukan wawancara dengan bagian bagian terkait dengan penelitian ini. Teknik pemeriksaan keabsahan data dapat dilakukan triangulasi. Menurut Moleong (2012) triangulasi adalah teknik pemeriksaan keabsahan data yang memanfaatkan sesuatu yang lain di luar data untuk keperluan pengecekan atau sebagai pembanding terhadap data tersebut. Hasil penelitian pada Perum Perhutani Jember adanya perbedaan pengukuran dalam laporan keuangan Perum Perhutani Jember dengan pengukuran menurut PSAK 69.
\end{abstract}

Kata Kunci: agrikultur, perhutani, PSAK 69, transformasi biologis.

\begin{abstract}
Biological transformation consists of the processes of growth, development, degeneration, production and procreation which cause qualitative and quantitative changes in the life of these animals and plants. Measurement of biological assets is necessary for companies so that measurements are carried out fairly in accordance with the contribution of biological assets in generating output and profits for the company. PSAK 69 aims to regulate accounting treatment and recognition related to agriculture. This research uses a qualitative approach, in which this research is conducted with interviews with the relevant sections of this research. The technique of checking the validity of the data can be triangulated. According to Moleong (2012) triangulation is a data validity checking technique that utilizes something other than the data for checking purposes or as a comparison to the data. The results of the research at Perum Perhutani Jember that there are differences in measurements in the financial statements of Perum Perhutani Jember with measurements according to PSAK 69.
\end{abstract}

Keywords: agriculture, forestry, PSAK 69, biologic transformation.

\section{Pendahuluan}

Tanaman merupakan aset biologis yang dimiliki oleh perusahaan yang bergerak di bidang perkebunan. Tanaman yang menghasilkan output dapat disebut aset karena karakteristik utama tanaman tersebut adalah digunakan untuk memproses output hingga tidak dapat bertumbuh dan menghasilkan produk agrikultur, bukan untuk dijual kembali. Ahmad Ridwan Abd (2011) menyatakan, hal yang membedakan aset biologis dengan aset yang lain adalah aset biologis dapat bertransformasi bahkan setelah mengeluarkan output. Transformasi biologis terdiri atas proses pertumbuhan, perkembangan, degenerasi, produksi, dan prokreasi yang menyebabkan perubahan secara kualitatif dan kuantitatif dalam kehidupan hewan dan tumbuhan tersebut. Adanya perbedaan pada transformasi inilah yang menyebabkan adanya perbedaan dalam pengukuran aset tetap dengan aset biologis. Pengukuran pada aset biologis diperlukan bagi perusahaan agar pengukuran dilakukan secara wajar sesuai dengan kontribusi aset biologis dalam menghasilkan output dan keuntungan bagi perusahaan.

Pencatatan, pengakuan, dan pengukuran aset biologis diatur oleh PSAK 69 tentang agrikultur yang diadopsi dari IAS 41 agriculture. PSAK 69 bertujuan untuk mengatur perlakuan akuntansi dan pengakuan yang berkaitan dengan agrikultur.

Berdasarkan uraian latar belakang di atas, maka permasalahan dalam penelitian ini dapat dirumuskan dalam bentuk pertanyaan penelitian yaitu:

1. Bagaimana perlakuan akuntansi pengakuan, pengukuran, dan pelaporan aset biologis pada laporan keuangan Perum Perhutani Jember?

2. Bagaimana perbandingan perlakuan pengakuan, pengukuran, dan pelaporan akuntansi aset biologis pada laporan keuangan Perum Perhutani Jember dengan perlakuan akuntansi aset biologis berdasarkan PSAK 69 "Agrikultur"?

* Corresponding author 


\section{Metode}

Metode penelitian dalam penelitian ini menggunakan metode kualitatif, dimana penelitian ini dilakukan wawancara dengan bagian bagian terkait dengan penelitian ini. Penelitian kualitatif menurut Moleong (2012) adalah penelitian dengan cara memahami fenomena yang dialami subjek penelitian dalam berperilaku, persepsi, motivasi, tindakan dideskripsikan dalam bentuk dan kata kata yang sama dan sesuai dengan keadaan yang sebenarnya.

\section{Jenis dan Sumber Data}

\section{Data primer}

Sekaran (2013) menjelaskan bahwa data primer merupakan data yang mengacu pada informasi yang diperoleh dari tangan pertama yang berkaitan dengan penilitan yang dilakukan. Sumber data primer bisa merupakan responden individu, narasumber, maupun koesioner. Sedangkan Narimawati (2008) menjelaskan bahwa data primer merupakan data yang dikumpulkan dari narasumber maupun responden yang dijadikan peneliti sebagai sarana mendapat informasi.

\section{Data sekunder}

Data sekunder diperoleh sehubungan dengan perusahaan yang telah di dokumentasikan berupa catatan transaksi, laporan keuangan dan lain-lain. Menurut sugiono (2008) data sekunder adalah sumber data yang di dapatkan peniliti sebagai pendukung data primer seperti buku bacaan, literature, dan lain-lain.

\section{Metode Analisis Data}

Teknik analisis data yang digunakan dalam penelitian ini adalah menggunakan metode analisis deskriptif kualitatif. Dengan metode analisis deskriptif kualitatif, data yang diperoleh dianalisis dengan mempelajari hasil yang didapatkan saat observasi, memaparkan hasil yang diolah, dan menjelaskan data-data yang diperoleh pada Perum Perhutani KPH Jember untuk mendapatkan gambaran yang jelas dan menyeluruh. Selanjutnya data yang sudah diperoleh dan diolah dibandingkan dengan teori yang berlaku dalam hal ini yang dibandingkan adalah pengakuan, pengukuran, dan pengungkapan aset biologis Perum Perhutani dengan perlakuan akuntansi yang berlaku dalam PSAK 69 "Agrikultur". Setelah mengetahui perbedaan pengakuan, pengukuran, dan pengungkapan dari data Perum Perhutani yang diolah dengan PSAK 69, penulis akan memberikan kesimpulan mengenai kesiapan perusahaan dalam pengunaan PSAK 69 serta faktor yang menghambat pemberlakuan PSAK 69 dalam perusahaan.

\section{Hasil dan Pembahasan}

\section{Hasil}

Perhutani merupakan Badan Usaha Milik Negara (BUMN) berbentuk Perusahaan Umum (Perum) yang memiliki tugas dan wewenang sebagai pengelola sumber daya hutan milik negara di Pulau Jawa dan Madura. Perhutani memiliki peran melindungi dan mendukung sistem kelestarian lingkungan, sistem sosial budaya, dan sistem perekonomian masyarakat perhutanan. PERUM Perhutani membagi hasil produksinya menjadi 2 bagian besar berupa produk kayu dan non-kayu. Produk kayu berasal dari tanaman yang menghasilkan kayu, yang selanjutnya menjadi produk tebangan dan hasil akhir menjadi log, sedangkan produk non kayu dihasilkan dari tanaman menghasilkan non-kayu yang selanjutnya menjadi produk agrikultur berupa getah pinus maupun minyak kayu putih dan hasil akhir menjadi produk olahan getah atau gondorukem

KPH Jember memiliki 3 tanaman pokok berupa tanaman menghasilkan kayu yaitu jati, sengon, dan tanaman pokok berupa tanaman menghasilkan non kayu yaitu pinus. Tanaman pokok ini menjadi produk utama yang dikembangkan oleh Perum Perhutani KPH Jember dan tersebar di berbagai daerah yang selanjutnya akan dikembangkan menjadi produk agrikultur. ada perbedaan perhitungan yang diterapkan oleh bagian akuntansi pusat untuk menghitung nilai aset. Tanaman aset berumur 6 tahun ke atas dan tanaman yang berumur 1-5 tahun. Untuk tanaman aset diatas 6 tahun, perhutani menggunakan perhitungan: Nilai Aset Tegakan = standing stock $\mathrm{x}(1-\mathrm{AK}) \mathrm{x}$ harga kayu. Perhitungan dilakukan pada Hutan Produksi (HP) dan Hutan Produksi Terbatas (HPT). Harga kayu ditentukan dari jenis kayu per sortimen, kayu jati menggunakan harga rata-rata per sortimen sesuai mutu tertentu per kelas KPH, sedangkan kayu rimba (mahoni, sono, pinus, damar, sengon, dan lain-lain) dari departemen kehutanan ditentukan sesuai mutu tertentu. Perhitungan tanaman muda umur 1-5 tahun menggunakan perhitungan fair value dengan metode discount factor cash flow berdasarkan volume tanaman umur 6 tahun atau lebih.

\section{Pengakuan}

Berdasarkan wawancara dengan bagian akuntansi Perum Perhutani, dikatakan bahwa KPH Jember melakukan perlakuan akuntansi sesuai dengan Perum Perhutani Jawa Timur. Tanaman aset biologis sudah dicatat dan diakui mulai dari penanaman bibit hingga tanaman tersebut ditebang atau sudah tidak dapat menghasilkan produk agrikultur lagi. Sedangkan biaya persiapan lahan, biaya perawatan untuk tahun pertama hingga tahun ke 5 dan biaya keamanan diakui sebagai biaya untuk pengembangan aset tetap. Produk agrikultur yang dihasilkan oleh perum perhutani getah pinus diakui sebagai persediaan aset biologis produk agrikultur, sedangkan pohon pinus diakui sebagai aset biologis penghasil produk agrikultur, untuk tanaman tebangan tahun pertama hingga tahun ke lima, aset biologis diakui sebagai aset biologis dalam pembangunan, tanaman tebang diatas 6 tahun yang belum siap tebang diakui sebagai aset biologis belum siap tebang, dan aset biologis tanaman tebangan yang siap ditebang diakui sebagai persediaan aset biologis siap tebang.

\section{Pengukuran}

Berdasar laporan keuangan tahun 2018 Perusahaan Umum (PERUM) Perhutani dan Entitas Anak, aset biologis diukur berdasar nilai wajar dikurangi biaya untuk menjual yang termasuk biaya transportasi ke pasar, biaya penjualan, dan lain-lain kecuali biaya keuangan dan pajak penghasilan. Sedangkan, untuk tanaman produktif yang belum menghasilkan diukur berdasar akumulasi biaya perolehan yang meliputi biaya persiapan lahan, penanaman, pemupukan, serta biaya umum termasuk kapitalisasi biaya pinjaman yang digunakan untuk membiayai pengembangan tanaman belum menghasilkan dan dalam pengembangan serta biaya tidak langsung lainnya. 


\section{Penyajian dan pengungkapan}

Perum perhutani mengklasifikasikan aset biologisnya menjadi 3 bagian yaitu: 1. Tanaman penghasil kayu; 2 . Tanaman penghasil non kayu; 3. Produk non kayu. Kemudian, hasil produk tersebut dikelompokkan menjadi 2 bagian, yaitu: kelompok aset lancar dan kelompok aset tidak lancar.

\section{Kelompok Aset Lancar}

a. Aset biologis produk agrikultur

Aset biologis produk agrikultur yaitu aset yang berasal dari produk yang dihasilkan tanaman yang menghasilkan produk non kayu berupa getah, daun kayu putih, dan getah karet.

\section{b. Aset biologis tanaman siap tebang}

Aset biologis tanaman siap tebang ysitu tanaman yang menghasilkan kayu yang siap diproduksi pada tahun berikutnya yang bersumber dari hasil tebangan dan dicatat sebesar Nilai Rencana Produksi tebangan

\section{Kelompok Aset Tidak Lancar}

\section{a. Aset tanaman (PSAK 16; aset tetap)}

Aset tanaman (aset tetap) yaitu kelompok tanaman yang menghasilkan produk non kayu/ produk agrikultur yang dinilai dari realisasi biaya tanaman tiap tahun (pinus, kayu putih, karet)

b. Aset biologis tanaman dalam pembangunan

Aset biologis tanaman dalam pembangunan yaitu kelompok tanaman yang menghasilkan kayu dengan usia tanam 1-5 tahun.

\section{c. Aset biologis tanaman belum siap tebang}

Aset biologis tanaman belum siap tebang yaitu kelompok tanaman yang menghasilkan kayu belum siap tebang/ diproduksi dengan usai tanam 6 tahun ke atas.

Tabel 1. Penyajian pada Neraca KPH Jember

\begin{tabular}{|c|c|}
\hline Nomor akun & Nama akun \\
\hline & ASET LANCAR \\
\hline 11861 & Aset Biologis Produk Agrikultur (ABPA) \\
\hline 118611001 & APBA getah pinus \\
\hline 118611002 & ABPA daun kayu putih \\
\hline 118611003 & ABPA getah karet \\
\hline 118621001 & $\begin{array}{l}\text { Aset Biologis Tanaman Siap tebang } \\
\text { ASET TIDAK LANCAR }\end{array}$ \\
\hline 13811 & Aset tanaman (PSAK 16) \\
\hline 138111001 & Aset tanaman pinus \\
\hline 138111002 & Aset tanaman kayu putih \\
\hline 138111003 & Aset tanaman karet \\
\hline 138211001 & $\begin{array}{l}\text { Aset biologis } \\
\text { pembangunan }\end{array}$ \\
\hline
\end{tabular}

\section{Pembahasan}

\section{Pengakuan}

Tanaman pokok pada Perum Perhutani KPH Jember yang sudah diberlakukan sesuai dengan PSAK 69 adalah pohon tebangan (jati, sengon), pohon penghasil produk agrikultur (pinus), dan hasil produk agrikultur (getah pinus) diakui sebagai persediaan. Tanaman jati memiliki umur rata-rata 40 tahun untuk menjadi aset biologis tanaman siap tebang. Sebelum menjadi aset biologis tanaman siap tebang, untuk tahun 1-5 tanaman jati termasuk aset biologis tanaman dalam pembangunan dan setelahnya dipindahkan menjadi aset biologis tanaman belum siap tebang Berdasarkan pengamatan pada laporan keuangan Perum Perhutani dan wawancara dengan bagian keuangan, Perum Perhutani belum sepenuhnya mengaplikasikan PSAK 69 karena banyaknya kendala yang dihadapi.

Tabel 2. Perbandingan pengakuan menurut Perum perhutani dan menurut PSAK 69

\begin{tabular}{llll}
\hline $\begin{array}{l}\text { Unsur Laporan } \\
\text { Keuangan terkait }\end{array}$ & $\begin{array}{c}\text { Pengakuan } \\
\text { Menurut } \\
\text { Perum } \\
\text { Perhutani }\end{array}$ & $\begin{array}{l}\text { Pengakuan } \\
\text { Menurut } \\
\text { PSAK 69 }\end{array}$ & $\begin{array}{c}\text { Standar } \\
\text { Akuntansi }\end{array}$ \\
\hline $\begin{array}{l}\text { Aset tanaman } \\
\text { Tanaman dalam } \\
\text { pembangungan } \\
\text { (jati dan sengon) }\end{array}$ & $\begin{array}{l}\text { Aset tetap } \\
\text { biologis }\end{array}$ & $\begin{array}{l}\text { Aset tetap } \\
\text { Aset } \\
\text { biologis }\end{array}$ & PSAK 16 \\
$\begin{array}{l}\text { Tanaman siap } \\
\text { tebang }\end{array}$ & $\begin{array}{l}\text { Aset } \\
\text { biologis }\end{array}$ & $\begin{array}{l}\text { Aset } \\
\text { biologis }\end{array}$ & PSAK 69 \\
$\begin{array}{l}\text { Produk agrikultur } \\
\text { getah pinus }\end{array}$ & $\begin{array}{l}\text { Persediaan } \\
\text { Persediaan }\end{array}$ & PSAK 14 \\
$\begin{array}{l}\text { getah pinus yang } \\
\text { masih menempel } \\
\text { di pohon }\end{array}$ & $\begin{array}{l}\text { Persediaan } \\
\text { Produk agrikultur }\end{array}$ & $\begin{array}{l}\text { Aset } \\
\text { Biologis }\end{array}$ & PSAK 69 \\
$\begin{array}{l}\text { yang selesai di } \\
\text { proses }\end{array}$ & $\begin{array}{l}\text { jual siap } \\
\text { (dibukukan } \\
\text { oleh kbm }\end{array}$ & Persediaan & PSAK 14 \\
& $\begin{array}{l}\text { industry } \\
\text { hasil hutan) }\end{array}$ & & \\
\hline
\end{tabular}

Sumber: data primer yang diolah

\section{Pengukuran}

Pada Perum Perhutani KPH Jember, tanaman diukur menggunakan revenue base yang konsepnya kurang lebih sama dengan biaya perolehan. Sedangkan aset biologis yang ada belum dapat diukur dengan andal, aset biologis dapat diukur menggunakan fair value less cost to sell atau diukur pada biaya perolehan dikurangi akumulasi penyusutan dan akumulasi kerugian penurunan nilai.

3. Penyajian dan pengungkapan

Berdasarkan PSAK 69 "Agrikultur" dijelaskan bahwa aset biologis dikelompokkan tergantung lamanya masa panen, untuk aset biologis yang kurang dari satu tahun masuk kedalam aset lancar, aset biologis yang masa tanamnya lebih dari satu tahun dimasukkan dalam aset tetap, sedangkan tanamannya termasuk 'bearer plants' yang diungkapkan secara terpisah sebagai aset tidak lancar dan termasuk PSAK 16 "Aset Tetap" laporan keuangan yang dibuat oleh perhutani tidak dicantumkan secara spesifik mengenai aset biologis dan tanaman produktif berupa buah dan unsur lain yang masih menempel pada tanaman tersebut. laporan yang dibuat oleh perhutani dan laporan keuangan yang disesuaikan dengan PSAK 69 memiliki beberapa perbedaan. Pada laporan keuangan yang dibuat oleh perusahaan, tidak dicantumkan secara spesifik jenis aset biologis yang terdapat pada aset lancar maupun aset tidak lancar. Hal ini mengindikasikan bahwa perusahaan belum sepenuhnya mengakui aset biologis secara rinci, dalam laporan keuangan yang dibuat oleh KPH Jember, akun hanya berupa aset tetap, tanpa dikelompokkan menjadi tanaman menghasilkan maupun tanaman belum menghasilkan, seharusnya perusahaan membedakan akun 
tanaman yang merupakan tanaman menghasilkan dan tanaman belum menghasilkan. Perusahaan hanya mendata tanaman produktif dan menggabungkan aset biologis dalam akun yang sama. Seharusnya produk yang sedang tumbuh harus diakui, diukur dan diungkapkan secara terpisah dengan tanaman menghasilkan, menurut PSAK 69 'Agrikultur'. Produk yang sedang tumbuh tersebut harus diakui sebagai salah satu aset biologis perusahaan yang diukur dengan menggunakan nilai wajar dikurangi dengan biaya untuk menjual.

Tabel 3. Perbedaan perlakuan akuntansi menurut Perum Perhutani Jember dan PSAK 69

\begin{tabular}{|c|c|c|}
\hline $\begin{array}{l}\text { Perlakuan } \\
\text { Akuntansi }\end{array}$ & $\begin{array}{l}\text { Menurut } \\
\text { Perum } \\
\text { Perhutani }\end{array}$ & $\begin{array}{l}\text { Menurut PSAK } 69 \\
\text { 'Agrikultur' }\end{array}$ \\
\hline Pengakuan & $\begin{array}{l}\text { Untuk tanaman } \\
\text { dalam proses } \\
\text { dan tanaman } \\
\text { agrikultur } \\
\text { diakui sebagai } \\
\text { aset tetap, hasil } \\
\text { produk } \\
\text { agrikultur } \\
\text { diakui sebagai } \\
\text { persediaan }\end{array}$ & $\begin{array}{l}\text { untuk tanaman diakui } \\
\text { sebagai aset tetap, } \\
\text { sedangkan untuk hasil } \\
\text { produk yang sedang } \\
\text { tumbuh dapat } \\
\text { dimasukkan dalam aset } \\
\text { lancar maupun aset } \\
\text { tetap menurut masa } \\
\text { tanaamnya }\end{array}$ \\
\hline Pengukuran & Revenue base & $\begin{array}{l}\text { Fair value less cost to } \\
\text { sell }\end{array}$ \\
\hline $\begin{array}{l}\text { Pengungkapan } \\
\text { dan penyajian }\end{array}$ & $\begin{array}{l}\text { Diungkapkan } \\
\text { dalam Laporan } \\
\text { Posisi } \\
\text { Keuangan }\end{array}$ & $\begin{array}{ll}\text { Diungkapkan } & \text { dalam } \\
\text { Laporan } & \text { Posisi } \\
\text { Keuangan } & \end{array}$ \\
\hline
\end{tabular}

\section{Simpulan}

Dalam praktiknya Perum Perhutani KPH Jember belum bisa 100\% menerapkan PSAK 69 dengan tepat dan optimal.hal ini dapat dilihat dari hasil perbandingan bahwa Perum Perhutani KPH Jember masih ada beberapa hal yang belum sesuai dengan PSAK 69. Perum Perhutani mengakui produk agrikultur yang masih menempel dipohon sebagai persediaan, tetapi PSAK 69 mengatakan bahwa produk agrikultur yang masih menempel di pohon tersebut harus diakui sebagai aset biologis. Perum Perhutani sudah mengungkapkan secara terpisah aset biologis (biological assets) dengan aset tetap menghasilkan (bearer assets). Penerapan PSAK 69 tentang "Aset Biologis" belum bisa dilakukanPerum Perhutani KPH Jember. Selama ini, Perum Perhutani KPH Jember hanya melakukan pencatatan sesuai dengan instruksi dari kantor pusat yang disesuaikan dengan Rencana Kerja dan Anggaran Perusahaan (RKAP) tanpa melakukan studi yang lebih spesifik.

\section{Referensi}

Abd, Ahmad Ridwan. 2011. Perlakuan Akuntansi Aset Biologis PT. Perkebunan Nusantara XIV Makassar. Makassar: Universitas Hassanudin.

Ariyanto; dkk. 2014. Penerapan PSAK Adopsi IAS 41 Agrikultur. Binus Business Review vol 5: 186-193.

Deloitte. 2016. Bearer Plants A New Life. India: Deloitte Touche Tohmatsu India.

Exposure Draft Kerangka Konseptual Pelaporan Keuangan.2019. Jakarta: Dewan Standar Akuntansi Keuangan - Ikatan Akuntan Indonesia

Martani, Dwi. 2012. Akuntansi Keuangan Menengah buku 1. Jakarta: Penerbit Salemba Empat

Moleong, Lexy J. 2012. Metodologi Penelitian Kualitatif. Bandung: PT. Remaja Rosdakarya

Narimawati, Umi. 2008. Metodologi Penelitian Kualitatif dan Kuantitatif, Teori dan Aplikasi. Bandung: Agung Medi.

Nurhandika, Arief. 2018. Implementasi Akuntansi Aset Biologis pada Perusahaan Perkebunan Indonesia. Jurnal Ekonomi, Bisnis, dan Akuntansi. Vol 20

Nurrahmaya,dkk. 2016. Analisis Perlakuan Aset Biologis Pada Laporan Keuangan. Skripsi. Bandung: Program Sarjana Ekonomi Universitas Widyatama

Pernyataan Standar Akuntansi Keuangan No. 1. 2015. Penyajian Laporan Keuangan. Jakarta: Dewan Standar Akuntansi Keuangan - Ikatan Akuntan Indonesia

Pernyataan Standar Akuntansi Keuangan No. 9. 2017. Aktiva Lancar dan Kewajiban Jangka Pendek. Jakarta: Dewan Standar Akuntansi Keuangan - Ikatan Akuntan Indonesia

Pernyataan Standar Akuntansi Keuangan No. 13. 2015. Properti Investasi. Jakarta: Dewan Standar Akuntansi Keuangan - Ikatan Akuntan Indonesia

Pernyataan Standar Akuntansi Keuangan No 16. 2017. Aset Tetap. Jakarta: Dewan Standar Akuntansi Keuangan - Ikatan Akuntan Indonesia

Pernyataan Standar Akuntansi Keuangan No. 19. 2009. Aset Tidak Berwujud. Jakarta: Dewan Standar Akuntansi Keuangan - Ikatan Akuntan Indonesia

Pernyataan Standar Akuntansi Keuangan No. 68. 2013. Nilai Wajar. Jakarta: Dewan Standar Akuntansi Keuangan - Ikatan Akuntan Indonesia

Pernyataan Standar Akuntansi Keuangan No. 69 (Efektif 1 Januari 2018). 2016. Aset Biologis. Jakarta: Dewan Standar Akuntansi Keuangan Ikatan Akuntan Indonesia

PriceWaterhouseCoopers. 2009. A Practical Guide to Accounting for Agricultural Assets. http:/pwc.com/ifrs

PriceWaterhouseCoopers. 2018. A Practical Guide to The New and Revised Indonesian Financial Accounting Standards for 2018. http:/pwc.com/id

Sekaran, Uma. Dan Bougie. R. (2013). Research Methods for Business: A Skill Building Approach. Sussex: John Wiley \& Sons

Sugiyono. 2008. Metode Penelitian Kuantitatife, Kualitatife, Dan R\&D. Bandung: ALFABETA

Rahmanto, Marta. 2018. Implementasi Psak 69 Pada PT Perkebunan Nusantara Xii Kabupaten Jember Unit Kebun Banjarsari. Skripsi. Jember: Program Sarjana Ekonomi Universitas Jember

Utomo, R. dan Khumaidah.N.L. 2014. Perlakuan Akuntansi Aset Biologis (tanaman kopi) pada PT. Wahana Graha Makmur. Surabaya. Gema Ekonomi. Vol 3: 85-95.

Wirgha, Putri. 2018. Analisis Perlakuan Akuntansi Aset Biologis Pada PT. Perkebunan Nusantara XII Ngrangkah Pawon. Skripsi. Jember: Program Sarjana Ekonomi Universitas Jember. 